\title{
Treatment of nephrogenic diabetes insipidus with hydrochlorothiazide and amiloride
}

\author{
Veronika Kirchlechner, Dieter Y Koller, Reiner Seidl, Franz Waldhauser
}

\begin{abstract}
Nephrogenic diabetes insipidus (NDI) is characterised by the inability of the kidney to concentrate urine in response to arginine vasopressin. The consequences are severe polyuria and polydipsia, often associated with hypertonic dehydration. Intracerebral calcification, seizures, psychosomatic retardation, hydronephrosis, and hydroureters are its sequelae. In this study, four children with NDI were treated with $3 \mathrm{mg} / \mathrm{kg} /$ day hydrochlorothiazide and $0.3 \mathrm{mg} / \mathrm{kg} / \mathrm{day}$ amiloride orally three times a day for up to five years. While undergoing treatment, none of the patients had signs of dehydration or electrolyte imbalance, all showed normal body growth, and there was no evidence of cerebral calcification or seizures. All but one had normal psychomotor development and normal sonography of the urinary tract. However, normal fluid balance was not attainable (fluid intake, 3.8-7.7 1/ $\mathrm{m}^{2} /$ day; urine output, $2.2-7.41 / \mathrm{m}^{2} /$ day). The treatment was well tolerated and no side effects could be detected. Prolonged treatment with hydrochlorothiazide/amiloride appears to be more effective and better tolerated than just hydrochlorothiazide. Its efficacy appears to be similar to that of hydrochlorothiazide/indomethacin but without their severe side effects. (Arch Dis Child 1999;80:548-552)
\end{abstract}

Keywords: hydrochlorothiazide; amiloride; nephrogenic diabetes insipidus; long term treatment

Nephrogenic diabetes insipidus (NDI) is a rare inherited disease characterised by the failure of the kidney to respond to arginine vasopressin (AVP) because of a receptor or postreceptor defect, despite raised serum concentrations of AVP. ${ }^{1}$ As a consequence, the kidney produces enormous quantities of hypotonic urine. Thus, patients with NDI have dramatic polyuria and polydipsia, and any episode of additional water loss (fever, diarrhoea, vomiting) may lead to potential life threatening dehydration and hypernatraemia, especially in infants and toddlers. A strong relation between repeated episodes of hypernatraemic dehydration and mental retardation, seizures, and cerebral calcifications has been documented. ${ }^{23}$ Furthermore, the course of NDI may also be complicated by dilatation of the urinary tract owing to excessive urine production ${ }^{45}$ and by growth failure, which is thought to be caused by inadequate energy intake. ${ }^{2}$
Treatment of NDI focuses on the reduction of polyuria to avoid dehydration and hypernatraemia and therefore on prevention of early and late onset complications. In 1959, Crawford and Kennedy introduced hydrochlorothiazide combined with a low sodium intake in the treatment of NDI, ${ }^{6}$ by which a reduction of the urine solute load of $20-50 \%$ can be expected. Long term treatment with hydrochlorothiazide, however, frequently results in hypokalaemia ${ }^{7}$ associated with cardiac arrhythmias. Potassium intake itself, required to prevent hypokalaemia, may result in gastrointestinal complications. ${ }^{8}$

In the 1980 s, prostaglandin synthesis inhibitors (such as indomethacin) were introduced in the treatment of NDI. The combination of indomethacin/hydrochlorothiazide has been described as being even more effective than indomethacin alone in diminishing urine production by $50-70 \% .{ }^{9}{ }^{10}$ However, hypokalaemia must still be expected, as well as other severe adverse effects induced by indomethacin, such as renal, gastrointestinal, and haematopoetic complications. ${ }^{11}$

Studies by Alon and Chan ${ }^{12}$ and Knoers and Monnens ${ }^{11}$ showed that the combination of hydrochlorothiazide/amiloride is as effective as the previous combination. In addition, no potassium intake is necessary and patients do not need to suffer the side effects of indomethacin.

However, there is no experience with long term usage of the combination hydrochlorothiazide/amiloride in the treatment of NDI. ${ }^{113}$ Here, we describe four children with NDI being treated with hydrochlorothiazide/amiloride over a period of one to five years.

\section{Patients and methods}

PATIENTS

Case 1

A boy (currently 4 years and 9 months old) was admitted to our clinic at the age of 2 months. Pregnancy and delivery were uneventful, birth weight $3404 \mathrm{~g}$, and birth length $54 \mathrm{~cm}$. The patient's history consisted of polyuria, lack of weight gain, refusal of oral fluid intake, and vomiting. In another hospital, NDI was suspected and treatment with hydrochlorothiazide initiated. Because of ongoing vomiting the patient was admitted to our department. After discontinuation of hydrochlorothiazide we found hypernatraemia, polyuria, and decreased urinary osmolality. The diagnosis was confirmed by fluid restriction and 1-desamino-8-D-arginine vasopressin (DDAVP) administration (table 1). 
Table 1 Clinical features of patients before treatment with hydrochlorothiazide and amiloroide

\begin{tabular}{|c|c|c|c|c|c|c|c|c|c|}
\hline Case & $\begin{array}{l}\text { Age* } \\
\text { (months) }\end{array}$ & $\begin{array}{l}\text { Serum } \\
\text { sodium } \\
(\text { mmol/l) }\end{array}$ & $\begin{array}{l}\text { Serum } \\
\text { potassium } \\
(\text { mmolll })\end{array}$ & $\begin{array}{l}24 \text { h urine } \\
\text { volume } \\
\text { (ml/kg bw) }\end{array}$ & $\begin{array}{l}24 \text { h urine } \\
\text { osmolality } \\
\text { (mmol/l) }\end{array}$ & $\begin{array}{l}\text { Urine osmolality } \\
\text { before DDAVP } \\
\text { (mmol/l) }\end{array}$ & $\begin{array}{l}\text { Urine osmolality } \\
\text { after DDAVP } \\
\text { (mmolll) }\end{array}$ & $\begin{array}{l}\text { Plasma AVP } \\
(p g / m l)+\ddagger\end{array}$ & $\begin{array}{l}\text { Genetic mutation of } V 2 \text { receptor } \\
\text { gene }\end{array}$ \\
\hline 1 & 6 & 161 & 4.7 & 384 & 83 & 128 & 135 & 3.25 & \\
\hline 2 & 5 & 160 & 4.7 & 360 & 89 & 190 & 210 & & Point mutation ( T975 $\rightarrow$ A) \\
\hline 3 & 14 & 166 & 6.1 & 432 & 118 & 64 & 152 & 3.0 & Point mutation $(\mathrm{T} 727 \rightarrow \mathrm{G})^{14}$ \\
\hline 4 & 33 & 145 & 5.8 & 336 & 82 & 82 & 105 & 3.1 & Point mutation $(\mathrm{T} 727 \rightarrow \mathrm{G})^{14}$ \\
\hline
\end{tabular}

${ }^{\star}$ At onset of treatment. $†$ While normally rehydrated. $¥$ Reference values mean (SD) $1.1(0.6) \mathrm{pg} / \mathrm{ml} .{ }^{15}$

Treatment with hydrochlorothiazide was resumed. In the following months, several episodes of fluid refusal and vomiting occurred and once even hypernatraemia $(161 \mathrm{mmol} / \mathrm{l})$ and hypokalaemia $(2.2 \mathrm{mmol} / \mathrm{l})$ were noticed. Thus, at the age of 6 months amiloride was added to the treatment. Subsequent examinations revealed minor abnormalities (for details see below).

Case 2

The second patient is a boy who is currently 1 year and 8 months old. He was delivered by caesarean section because of inadequate labour at 38 weeks of gestation, with a birth weight of $4148 \mathrm{~g}$ and a birth length of $54 \mathrm{~cm}$; parents are not consanguineous. The patient's history consisted of screaming attacks, agitation, and fever from the 2 nd day of life. Further examinations revealed hypernatraemia and increased serum osmolality. After diagnosis of NDI in another hospital, treatment with indomethacin was initiated. However, at the age of two months the boy was admitted to our hospital because of fever and fluid refusal. After discontinuation of treatment and subsequent fluid restriction, the diagnosis of NDI was confirmed owing to a lack of response to DDAVP (table 1). Thereafter, treatment with hydrochlorothiazide was initiated and amiloride was added at the age of 5 months. During the 1 st year of life the patient had been hospitalised twice as a result of vomiting without electrolyte imbalance. His growth and weight gain are adequate.

Case 3

This boy is now 5 years and 11 months old. Pregnancy and delivery were uneventful, birth weight $3190 \mathrm{~g}$, and birth length $50 \mathrm{~cm}$. At the age of 10 days he was first admitted to our hospital because of fever, diarrhoea, and hypertonic dehydration, with a serum sodium concentration of $166 \mathrm{mmol} / \mathrm{l}$, potassium of $6.1 \mathrm{mmol} / \mathrm{l}$, and serum osmolality of $357 \mathrm{mmol} / \mathrm{l}$, whereas urinary osmolality was only $64 \mathrm{mmol} / \mathrm{l}$. Despite these data, polyuria was noticed. Diabetes insipidus centralis was suspected and treatment with DDAVP initiated. Because the boy continued to suffer from polyuria with low urinary osmolality, a dehydration test with subsequent DDAVP administration was performed and the diagnosis of NDI was established. The patient was first treated with hydrochlorothiazide and at the age of 14 months amiloride was added. The boy's development is satisfactory and no electrolyte imbalance has been noticed since then.

Case 4

This patient is a girl of 7 years and 7 months, sister of case 1. Pregnancy and delivery were uneventful, birth weight $3090 \mathrm{~g}$, and birth length $50 \mathrm{~cm}$. At 10 days of age the girl was admitted to another hospital because of diarrhoea and hypertonic dehydration. Blood culture revealed infection with Escherichia coli and antibiotics were administered. Two years later, after delivery of her brother and his diagnosis of NDI, detailed re-examination for the occurrence of NDI was performed. At normal serum electrolyte concentrations and normal serum osmolality, polyuria, and polydipsia with low urinary osmolality $(82 \mathrm{mmol} / \mathrm{l})$ were identified. Because neither fluid restriction nor DDAVP resulted in an increase in urine osmolality, the diagnosis of NDI was established and confirmed by genetic analysis (table 1). ${ }^{14}$

After treatment with hydrochlorothiazide for six months, amiloride was added owing to persistent hypokalaemia. Since that time, serum electrolyte concentrations have been in the normal range continuously and she has shown normal growth and weight gain.

\section{METHODS}

Diagnosis of NDI

After two 24 hour urine collections and assessment of fluid intake, fluid was restricted for a period of four to eight hours followed by intravenous application of DDAVP $(1 \mu \mathrm{g}$ for infants and $2 \mu \mathrm{g}$ for toddlers). We determined urine volume and osmolality, as well as serum electrolyte concentrations and osmolality, before and after administration of DDAVP (table 1).

At well hydrated conditions blood was drawn for the assessment of AVP by means of a recently published radioimmunoassay. ${ }^{15}$

Analysis of the vasopressin type 2 (V2) receptor gene was performed at the department of human genetics, University Children's Hospital, Nijmegen, the Netherlands. ${ }^{14}$

\section{Treatment and follow up}

For a period of one to five years, we treated the four patients with NDI with a combination of hydrochlorothiazide ( $3 \mathrm{mg} / \mathrm{kg} / \mathrm{day})$ and amiloride $(0.3 \mathrm{mg} / \mathrm{kg} /$ day $)$ orally three times a day. In addition, salt restriction was recommended but a specific diet was not required. We instructed the parents to take care that the children received a generous fluid supply, especially during early childhood. In case of vomiting, diarrhoea, refusal of fluid intake, or fever, the parents were told to contact us immediately.

We routinely checked height, weight, and serum concentrations of electrolytes, uric acid, and creatinine several times each year. Bone age was determined annually according to the method of Greulich and Pyle. ${ }^{16}$ 

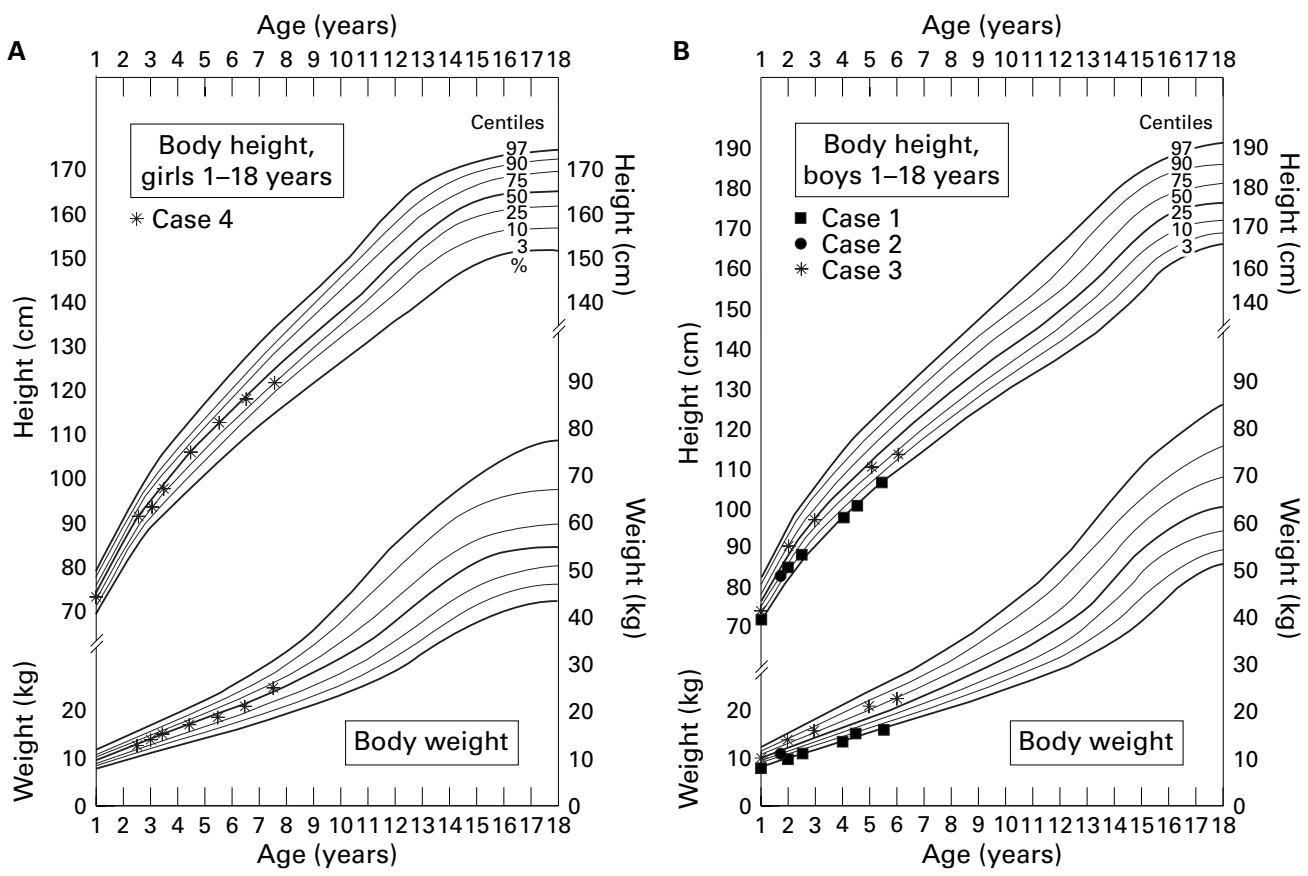

Figure 1 Length and weight charts for one girl (A) and three boys (B) with nephrogenic diabetes insipidus.

During the last year, we performed 24 hour fluid balance, ultrasonic examination of the kidney and the urinary tract, cranial computer tomography (CT), and investigation of psychomotoric development in each patient.

\section{Results}

SOMATIC DEVELOPMENT

The patients all demonstrated adequate growth and weight gain (fig 1), with minor delay in bone maturation (table 2).

NEUROLOGICAL AND MENTAL DEVELOPMENT Three of the four patients showed normal psychomotor development; only one (case 1) displayed discrete signs of motor retardationwalking at the age of 18 months, mild muscular hypotony, and delay in coordination.

All the patients demonstrated a normal cranial CT scan, and in particular, no signs of intracerebral calcifications were detectable as described after hypertonic dehydration. ${ }^{17-20}$

FLUID AND ELECTROLYTE BALANCE

Mean (SD) serum concentrations of repeated measurements at the routine checks outlined were as follows: sodium, $139.5(2.6) \mathrm{mmol} / 1$ ( $\mathrm{n}=32$; normal range, 135-147); potassium, $4.1(0.6) \mathrm{mmol} / \mathrm{l}(\mathrm{n}=32$; normal range, 3.45.4); chloride, 101.9 (3.4) mmol/ $1 \quad(\mathrm{n}=32$; normal range, 95-112); uric acid, 4.1 (1.0) $\mathrm{mg} / \mathrm{l} \quad(\mathrm{n}=23$; normal range, 2.0-6.2); and creatinine, $0.41(0.10) \mathrm{mg} / 1(\mathrm{n}=15$; normal range, $0.2-0.8$ ). Each individual value was within the specified normal range.

However, 24 hour urine volumes were substantially increased to $2.2-7.4 \mathrm{l} / \mathrm{m}^{2} /$ day (normal range, $0.9-1.0 \mathrm{l} / \mathrm{m}^{2} /$ day) ) $^{21}$ (table 2 ). Every patient suffered either from enuresis nocturna or nocturia (cases 1 and 4). At a sonographic examination, three of four children showed a regular kidney image without signs of a non-obstructive urinary tract dilatation. However, in case 1, first signs of hydronephrosis grade 1 with normal morphology of the kidney were detected at the age of 4 years and 8 months. He was also the patient with the highest urine production $\left(7.4 \mathrm{l} / \mathrm{m}^{2} /\right.$ day $)$. Exaggerated urine flow has been repeatedly reported as a cause of urinary tract dilatation. ${ }^{45}$

HOSPITALISATION

After starting treatment with hydrochlorothiazide/amiloride, the children were admitted to our hospital three times over a period of 14.5 years of treatment (case 1 once, case 2 twice, cases 3 and 4 not admitted). The admissions were required because of febrile infections, diarrhoea, or refusal of fluid intake; even in these situations neither severe dehydration nor electrolyte imbalance was observed. The treatment of the patients was limited to intravenous fluid substitution, tube feeding, and control of fluid and electrolyte balance. Almost all the admissions occurred during the 1st year of life,

Table 2 Clinical features of patients while on treatment with hydrochlorothiazide and amiloroide

\begin{tabular}{|c|c|c|c|c|c|c|c|c|}
\hline Case & $A g e^{\star}$ & Bone $^{\star}$ age & $\begin{array}{l}\text { Fluid intake } \\
\left({\left.\mathrm{l} / \mathrm{m}^{2} / \text { day }\right)}\right.\end{array}$ & $\begin{array}{l}\text { Urine volume } \\
\left(l / m^{2} / \text { day }\right)\end{array}$ & $\begin{array}{l}\text { Serum * sodium } \\
(\mathrm{mmol} / \mathrm{l})\end{array}$ & $\begin{array}{l}\text { Serum } \\
(\mathrm{mmol} / \mathrm{l})\end{array}$ & $\begin{array}{l}\text { Body* } \\
\text { weight (kg) }\end{array}$ & $\begin{array}{l}\text { Body }{ }^{\star} \text { height } \\
\text { (cm) }\end{array}$ \\
\hline 1 & 4 y $10 \mathrm{~m}$ & 4 y $3 \mathrm{~m}$ & 7.7 & 7.4 & 139 & 3.0 & 15.7 & 102.0 \\
\hline 2 & 1 y $8 \mathrm{~m}$ & $1 \mathrm{y} 1 \mathrm{~m}$ & 4.0 & 3.3 & 145 & 4.7 & 10.2 & 83.1 \\
\hline 3 & $5 \mathrm{y} 11 \mathrm{~m}$ & $6 \mathrm{y}$ & 5.9 & 3.5 & 140 & 3.6 & 21.3 & 113.5 \\
\hline 4 & 7 y $7 \mathrm{~m}$ & $8 \mathrm{y}$ & 3.8 & 2.2 & 141 & 3.3 & 22.6 & 125.0 \\
\hline
\end{tabular}

^At last examination. 
because infants are very sensitive to fluid loss and the oral administration of fluid may be extremely difficult at that age.

SIDE EFFECTS

No adverse effects as a result of the treatment with hydrochlorothiazide/amiloride were reported, either by the patients or their parents. Repeated medical examinations did not reveal any adverse reactions either.

\section{Discussion}

As demonstrated by the growth charts (fig 1), long term treatment with hydrochlorothiazide/ amiloride resulted in normal growth and there was normal bone maturation in our patients with NDI (table 2). Only one patient (case 1) showed height and weight development at the third centile. In inadequately treated patients with NDI, failure of normal growth has been frequently seen and attributed to reduced intake of solid food because of very high fluid consumption. $^{22}$

None of the children presented with intracerebral calcifications or seizures. Psychomotor development was also within the normal range and only one patient (case 1) suffered from discrete motor deficiencies. Intracerebral calcifications and seizures have been noticed repeatedly in NDI. They have been ascribed to endothelial injuries caused by hypertonic dehydration occurring particularly during infancy, when the patients are not able to compensate for fluid losses by themselves. ${ }^{17-20}$

In less recent studies, especially, psychological disturbances and mental retardation were reported repeatedly in children with NDI. ${ }^{23}{ }^{24}$ A causal association with recurrent dehydration, electrolyte shift, and consequent endothelial damage was assumed. ${ }^{23}{ }^{25}$ Alternatively, the permanent requirement for drinking and voiding may lead per se to reduced periods of undisturbed concentration and placid behaviour in playing and social integration. Because retardation appears to be most prominent in the first 2 years of life and it can be caught up later in childhood, electrolyte imbalance with its sequelae may play a more important role in the development of these symptoms. Interestingly, in more recent studies, mental retardation is being described less frequently, which might be the result of improvement in treatment modalities. ${ }^{24}$

After starting treatment with hydrochlorothiazide/amiloride, none of our patients showed any signs of dehydration. Fluid intake and urine output, however, were very high and the children had to consume fluid during the night. All suffered either from enuresis nocturna or nocturia. The amount of urine produced by our patients $\left(2.2-7.41 / \mathrm{m}^{2} /\right.$ day) was similar to the quantities reported by others $^{1112}$ and for patients treated with hydrochlorothiazide/indomethacin. ${ }^{26}$ Despite this large fluid turnover, normal energy intake with adequate growth and weight gain were obviously attainable (fig 1). Only one child (case 1) displayed signs of mild hydronephrosis at the age of 4.5 years. In patients with NDI, non-obstructive dilatation of the urinary tract (that is, hydronephrosis, megaureter) is regarded as a consequence of excessive urine production. ${ }^{4}$

We have never observed the known side effects of monotherapy with hydrochlorothiazide, such as hypokalaemia or hyperuricaemia, ${ }^{7}$ or of the combination hydrochlorothiazide/indomethacin, such as renal or gastrointestinal complications. ${ }^{11}$ So far, the morbidity of our children has been relatively low and the admissions mentioned have been of short duration and somewhat prophylactic, to avoid dehydration.

During the past few years, knowledge of the pathophysiology and genetics of NDI has increased remarkably. In healthy subjects, AVP acts to increase the permeability of the luminal membrane in the collecting ducts to water by insertion of water channels (aquaporine 2) via V2 receptors by means of a cAMP dependent mechanism. This permits the water to flow by passive diffusion from the tubule into the hypertonic medullary interstitium in the kidney, and the urine can be concentrated. AVP induces incorporation of aquaporine 2 into the membrane via coated pits, as well as recycling via coated vesicles. Unresponsiveness to AVP or a deficiency of AVP results in impaired incorporation and recycling of water, which means that water channels are stored in cytoplasmatic vesicles. ${ }^{27-29}$ Patients with NDI may have one of two defects, either a V2 receptor defect (X chromosomal recessive) ) $^{30-32}$ or rarely an aquaporine 2 defect (autosomal recessive). ${ }^{1433} 34$ In both cases, the clinical symptoms are alike and there is still no causal treatment available. ${ }^{1}$

In conclusion, long term treatment of our patients with NDI with hydrochlorothiazide/ amiloride has resulted in normal growth and normal mental development. Furthermore, the treatment seems to be more effective and better tolerated than just hydrochlorothiazide. Its efficacy appears to be similar to that of hydrochlorothiazide/indomethacin, without the severe side effects reported with this combination. Urinary volume can be reduced but not to normal volumes; thus, polyuria and polydipsia will continue, but in a less intensive form than in untreated patients.

The authors thank Dr EH Hoefsloot, University Hospital Nijmegen, for performance of the DNA analysis in case 2 .

1 Bichet DG, Oksche A, Rosenthal W. Congenital nephrogenic diabetes insipidus. 7 Am Soc Nephrol 1997;8:1951-8. Knoers N, Monnens LA. Nephrogenic diabetes insipidus: clinical symptoms, pathogenesis, genetics and treatment. Pediatr Nephrol 1992;6:476-82.

3 Reeves WB, Andreoli TE. Nephrogenic diabetes insipidus. In: Scriver, CR, Beaudet AL, Sly WS, Valle D, eds. The metabolic and molecular bases of inherited disease. New York: McGraw Hill 1995:3045-71

4 Stevens S, Brown BD, McGahan JP. Nephrogenic diabetes insipidus: a cause of severe nonobstructive urinary tract dilatation. F Ultrasound Med 1995;14:543-5.

5 Uribarri J, Kaskas M. Hereditary nephrogenic diabetes insipidus and bilateral nonobstructive hydronephrosis. Nephron 1993;65:346-9.

6 Crawford JD, Kennedy GC. Chlorothiazide in diabetes insipidus. Nature 1959;183:891-2.

7 Morgan DB, Davidson C. Hypokalaemia and diuretics: an analysis of publications. BMF 1980;280:905-8.

8 McMahon FG, Ryan JR, Akdamar K, Ertan A. Upper gastrointestinal lesions after potassium chloride supplements: a controlled clinical trial. Lancet 1982;2: 1059-61. 
9 Monn E. Prostaglandin synthetase inhibitors in the Monn E. Prostaglandin synthetase inhibitors in the treatment of nephroge
Scand $1981 ; 70: 39-42$.

10 Jakobsson B, Berg U. Effect of hydrochlorothiazide and indomethacin treatment on renal function in nephrogenic diabetes insipidus. Acta Paediatr 1994;83:522-5.

11 Knoers N, Monnens LA. Amiloride-hydrochlorothiazide versus indomethacin-hydrochlorothiazide in the treatment of nephrogenic diabetes insipidus. F Pediatr 1990;117:499-502

12 Alon U, Chan JC. Hydrochlorothiazide-amiloride in the treatment of congenital nephrogenic diabetes insipidus. $A m$ f Nephrol 1985;5:9-13.

13 Uyeki TM, Barry FL, Rosenthal SM, Mathias RS. Successful treatment with hydrochlorothiazide and amiloride in an infant with congenital nephrogenic diabetes insipidus. Pediatr Nephrol 1993;7:554-6.

14 van Lieburg AF, Verdijk MA, Schoute F, et al. Clinical phenotype of nephrogenic diabetes insipidus in females heterozygous for a vasopressin type 2 receptor mutation. Hum Genet 1995;96:70-8.

15 Kluge M, Riedl S, Hofmann B, Hartmann J, Waldhauser F. Improved procedure for determination of argininevasopressin in plasma: role of premeasurement sample treatment and reference values in children. Clin Chen 1999;45:98-103.

16 Greulich WW, Pyle SI. Radiographic atlas of skeletal development of the hand and wrist. Stanford: Stanford University Press, 1950.

17 Nozue T, Uemasu F, Endoh H, Sako A, Takagi Y, Kobayashi A. Intracranial calcifications associated with nephrogenic diabetes insipidus [see comments]. Pediat Nephrol 1993;7:74-6.

18 Schofer O, Beetz R, Kruse K, Rascher C, Schutz C, Bohl J. Nephrogenic diabetes insipidus and intracerebral calcification. Arch Dis Child 1990;65:885-7.

19 Tohyama J, Inagaki M, Koeda T, Ohno K, Takeshita K. Intracranial calcification in siblings with nephrogenic diabetes insipidus: CT and MRI. Neuroradiology 1993;35: 553-5.

20 Nunes ML, da Costa JC, Severini MH. Early onset bilateral calcifications and epilepsy. Pediatr Neurol 1995;13:80-2.

21 Referenzwerte. In: Universitäts-Kinderklinik B. Berner Datenbuch der Pädiatrie. Stuttgart, New York: Gustav Fischer Verlag, 1998:713
22 Knoers N, van Lieburg AF, Monnens LA, Van Oost BA, Deen PM, Van Os C. Aquaporins: from physiology to nephrogenic diabetes insipidus. Adv Nephrol Necker Hosp 1996;25:257-3.

23 Macaulay D, Watson M. Hypernatraemia in infants as a cause of brain damage. Arch Dis Child 1967;42:485-91.

24 Hoekstra JA, van Lieburg AF, Monnens LA, Hulstijn Dirkmaat GM, Knoers VV. Cognitive and psychosocial functioning of patients with congenital nephrogenic diabetes insipidus. Am f Med Genet 1996;61:81-8.

25 Schofer O, Beetz R, Bohl J, Bornemann A, Oepen J, Spranger J. Mental retardation syndrome with renal concentration deficiency and intracerebral calcification [see comments]. Eur F Pediatr 1990;149:470-4.

26 Libber S, Harrison H, Spector D. Treatment of nephrogenic diabetes insipidus with prostaglandin synthesis inhibitors. $\mathcal{F}$ Pediatr 1986;108:305-11.

27 van Lieburg AF, Knoers NV, Deen PM. Discovery of aquaporins: a breakthrough in research on renal water aquaporins: a breakthrough in research
transport. Pediatr Nephrol 1995;9:228-34.

28 Bichet DG. Vasopressin receptors in health and disease. Kidney Int 1996;49:1706-11.

29 Bichet DG. Nephrogenic diabetes insipidus. Semin Nephrol 1994;14:349-56.

30 Rosenthal W, Seibold A, Antaramian A, et al. Molecular identification of the gene responsible for congenital nephrogenic diabetes insipidus. Nature 1992;359:233-5.

31 Bichet DG, Hendy GN, Lonergan M, et al. X-linked nephrogenic diabetes insipidus: from the ship Hopewell to rogenic diabetes insipidus: from the ship Hopewel
RFLP studies. Am $\mathcal{F}$ Hum Genet 1992;51:1089-102.

32 Bichet DG, Arthus MF, Lonergan M, et al. X-linked nephrogenic diabetes insipidus mutations in North America and the Hopewell hypothesis. F Clin Invest 1993; 92:1262-8.

33 Deen PM, Verdijk MA, Knoers NV, et al. Requirementof human renal water channel aquaporin-2 for vasopressindependent concentration of urine. Science 1994;264: 92-5.

34 van Lieburg AF, Verdijk MA, Knoers VV, et al. Patients with autosomal nephrogenic diabetes insipidus homozygous for mutations in the aquaporin 2 water-channel gene. $A m \mathcal{F}$ Hum Genet 1994;55:648-52. 